\title{
Operative Management of Late Presented Displaced Lateral Condyle Fracture of Humerus in Children

\author{
Rajendra Sanjel Chhetri, ${ }^{1,2}$ Indra Dhakal, ${ }^{1}$ Gopal Gnawali'
}

'Department of Orthopedics, Lumbini Zonal Hospital, Butwal, Nepal, ${ }^{2}$ Department of Orthopedics, Lumbini Hospital and technical college, Butwal, Nepal.

Introduction: Management of late presented displaced fracture of lateral condyle of humerus in children is controversial, many recommend conservative management due to fear of complications like avascular necrosis but recently many are advocating for operative management with good results hence we studied the outcome of operative management in late presented displaced lateral condyle fracture of humerus in children.

Methods: We studied 22 children aged between 4 to 11 years, presenting 3 to 16 weeks from injury. All underwent open reduction and internal fixation with Kirschner wires with or without additional screw and followed up for average 18.05 months. Elbow range of motion, angular or local deformity, premature fusion of physis, avascular necrosis and fracture union were noted and analyzed using modified Aggarwal et al criteria.

Results: We had 9 (40.91\%) excellent, 5 (22.73\%) good, 5 (22.73\%) fair, $3(13.63 \%)$ poor result. Overall satisfactory results were seen in 19 (86.37\%); 3 (13.63\%) had poor result, one due to AVN, two due to premature fusion of physis and visible local deformity. All poor result were seen among delay of operation 6 weeks or later. There was significant improvement of elbow range of motion and all fracture united.

Conclusions: Outcome of operation without bone grafting on lateral condyle fracture of humerus in children who presents late up to 5 weeks are excellent; whereas outcome of delayed operation up to 16 weeks also gives good functional recovery and union.

Keywords: lateral condyle fracture; late presentation; operative management.

\section{INTRODUCTION}

Late presentation of displaced lateral condyle fracture is often seen in Nepal mainly due to initial misdiagnosis and mismanagement. When presented late there is dilemma between conservative versus operative management due to fear of complications like avascular necrosis. ${ }^{1,2}$ Recently many advocate for operative management to avoid nonunion, deformity, loss of elbow motion and tardy ulnar palsy like complications. ${ }^{3-5}$

Vascularity of lateral condyle of humerus enters through posterior soft tissue attachment. ${ }^{1,3,6}$ Preservation of posterior soft tissue is utmost important to avoid complications. Late presented displaced fracture is difficult to reduce anatomically due to fibrosis, sclerosis and shortening of common extensor, hence lengthening of common extensor with multiple incisions helps to achieve reduction. ${ }^{7,8}$

Correspondence: Dr. Rajendra Sanjel Chhetri, Department of Orthopedics, Lumbini Zonal Hospital, Butwal, Nepal. Email: sanjelr@ gmail.com, Phone: +977-9857028329. 
Chhetri et al. Operative Management of Late Presented Displaced Lateral Condyle..

We opted to evaluate the outcome of operative management in late presented displaced lateral condyle fracture in children presenting 3 weeks or later, protecting posterior soft tissue and making few incisions on common extensor to facilitate reduction.

\section{METHODS}

This observational study was carried out at Lumbini Zonal Hospital and Lumbini Hospital and Technical College Butwal, Nepal from August 2012 to October 2017. Children with less than 12 years of age visiting hospital with displaced lateral condyle fracture of humerus presenting 3 weeks or later from injury were admitted. Ethical permission was obtained from Institutional Review Committee and written consent were obtained. Children with open fracture, fracture associated with other fracture or dislocation of elbow and age more than 12 years were excluded from the study. History taking and examination including initial elbow range of motion were recorded. Jacob et al classification was used. ${ }^{1}$ Oblique radiographs were obtained to clear doubt when needed..$^{9,10}$

Operation done on routine basis, using lateral approach; special attention given to posterior soft tissue attachment not to jeopardize vascularity. Fracture surfaces curetted meticulously to cancellous bone, multiple incisions made on contracted common extensor whenever needed to obtain satisfactory reduction. Fragment stabilized rigidly with divergent, one horizontal and one oblique Kirshner wire ( $\mathrm{K}$ wire), tips bent and buried beneath skin. If rigid fixation not achieved due to long standing contracture or fibrosis or if the fragment was large enough; one horizontal $\mathrm{K}$ wire and one $4 \mathrm{~mm}$ partial threaded oblique cancellous screw was used. Above elbow plaster slab was used for three weeks followed by physiotherapy. Children were asked for regular follow up. Hard wares removed after solid bony union between 3-6 months. Bony alignment, union, elbow range of motion (ROM), any angular or local deformity, premature fusion of physis (PFP), presence of lateral spur and sign of avascular necrosis (AVN) as well as any other complications were recorded.

Aggarwal et al criteria was used to evaluate the outcome as it takes account of functional, angular and local deformities as well radiological findings. ${ }^{11}$ They were divided in three groups; in group one those operated within 3-5 weeks; in second group, those operated 6-9 weeks and in third group those operated 10-16 weeks from initial injury. Result thus obtained were analyzed using standard statistical tools.

\section{RESULTS}

There were total 22 cases, 20 boys and 2 girls, average age 6.8 years (range $3-11$ years). Seventeen $(77.27 \%$ ) were Jacob type three and five $(22.73 \%)$ were type two. Average delay (from trauma to operation) was 5.86 week (range 3-16 weeks). Average follow up was 18.05 months (range 6-60 months).

\begin{tabular}{|c|c|c|c|}
\hline $\begin{array}{l}\text { Delay from } \\
\text { trauma to } \\
\text { operation }\end{array}$ & $\begin{array}{l}\text { Average } \\
\text { Initial ROM } \\
\text { (Degree) }\end{array}$ & $\begin{array}{l}\text { Average } \\
\text { Final ROM } \\
\text { (Degree) }\end{array}$ & $\begin{array}{l}\text { Gain in ROM } \\
\text { (Degree) }\end{array}$ \\
\hline 3-5 weeks & 27 & 125 & 98 \\
\hline 6-9 weeks & 50 & 121 & 71 \\
\hline $\begin{array}{l}10-16 \\
\text { weeks }\end{array}$ & 55 & 113 & 58 \\
\hline
\end{tabular}

Initial average arc of elbow ROM was 38.18 degree (range 10-75\%); final average arc of elbow ROM was $122.73^{\circ}$ (range $110-130^{\circ}$. The improvement of final arc of elbow ROM after operation was statistically significant (paired t test $P<0.001, S D 24.44$ ). It was interesting to observe average $57.5^{\circ}$ of initial ROM arc in 6-16 weeks group was better than average $27.14^{\circ}$ in $3-5$ weeks group ( student $t$ test, $P<0.001, \mathrm{SE} 1$ 3.34, SE2 7.19 ).

\begin{tabular}{|llllll|}
\hline \multicolumn{6}{|l|}{ Table 2. Delay of operation and outcome. } \\
\hline $\begin{array}{l}\text { Delay } \\
\text { (weeks) }\end{array}$ & $\begin{array}{l}\text { Numbers } \\
\text { of cases }\end{array}$ & Excellent & Good & Fair & Poor \\
$3-5 \mathrm{~W}$ & 14 & 8 & 4 & 2 & 0 \\
$6-9 \mathrm{~W}$ & 4 & 1 & 1 & 1 & 1 \\
$10-16$ & 4 & 0 & 0 & 2 & 2 \\
W & & & & & \\
\hline
\end{tabular}

We had 9 excellent, 5 good, 5 fair, 3 poor result. Overall satisfactory results were seen in 19 (86.36\%), three $(13.64 \%)$ had poor result; one due to $A V N$, and two due to Premature fusion of physis and visible local deformity. All poor result were seen among delay of operation 6 weeks or later and 2 out of 4 had poor result when operated 10 weeks or later but all poor result had good functional regain and bony union. 
Chhetri et al. Operative Management of Late Presented Displaced Lateral Condyle...

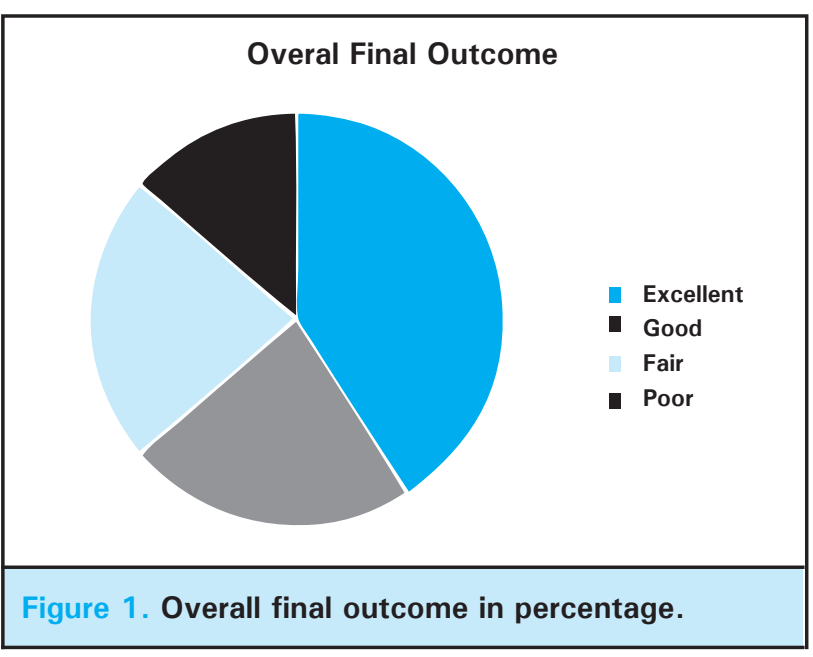

Sixteen children $(72.73 \%)$ had visible radiological lateral spur but only two $(9.09 \%)$ had visible deformity at local site. Four $(18.18 \%)$ had alteration in carrying angle of up to $6^{\circ}$ of valgus and $5^{\circ}$ of varus. We had two cases of premature fusion of physis (Final ROM 115 ${ }^{\circ}$ ) and one avascular necrosis (Final ROM 130\%). Pin site infection occurred in 3. All fractures united well and all parents were satisfied with final outcome.

\begin{tabular}{|lll|}
\hline Table & 3. List of complications. \\
\hline S. N. & Complications observed & $\mathrm{n}$ \\
1. & Avascular necrosis of lateral condyle & 1 \\
2. & Premature physis closure & 2 \\
3, & Cubitus valgus/varus deformity & 4 \\
4, & Lateral spur on final X-ray & 16 \\
5. & Visible deformity at local site & 2 \\
6. & Non union & 0 \\
7. & Pin site infection & 3 \\
\hline
\end{tabular}

\section{DISCUSSION}

Late presentation of displaced lateral condylar fracture is not uncommon in developing countries like Nepal mainly due to initial misdiagnosis or mismanagement; though patient is seeking medical help from the beginning, unfortunately reaches proper facility late hence we did not label them as neglected cases. The fracture is prone for late displacement even inside plaster splintage. ${ }^{13}$ Seeking local bone healers or poor economy had also contributed for late presentation. Common reason of presentation were pain, stiffness and local bony protuberance. Taking oblique $\mathrm{X}$-rays especially internal oblique along with standard anteroposterior and lateral views helps better in determining amount of displacement. ${ }^{9,10}$ Average initial elbow ROM arc in delay of 3-5 weeks group was $27.14^{\circ}$ improved to $125.7^{\circ}$, whereas initial average ROM arc in delay of 6-16 weeks group was $57.5^{\circ}$ improved to $117.5^{\circ}$. This difference in initial average ROM arc might be because later presenting children have more time for moving elbow to regain better range of motion but more the delay of operation lesser is the final regain.

There are many rating system to evaluate elbow but Aggarwal et al criteria takes care of many aspects of complications like angular and local deformity, premature fusion of physis and avascular necrosis hence we used this criteria to evaluate our outcomes. ${ }^{11,12}$

Fresh displaced fracture is considered as fracture of necessity requiring operation. ${ }^{13}$ We found operating on late presented child up to 16 weeks from initial trauma also gives good functional outcome and chance of AVN is not that high as feared before. In our study, only one (4.55\%) had AVN but final elbow range of motion was full in 25 months of follow up, some revascularization of condyle was noted and child along with parent were happy with the functional outcome.

Radiological appearance of lateral spur were seen in 16 $(72.73 \%)$ but obvious local deformity was noted only in $2(9.09 \%)$. Neither presence nor size of lateral spur affects the final outcome, most of the time it is barely noticeable clinically. ${ }^{14}$ Furthermore 2 premature fusion of physis and pin site infections in our study might have given visible local deformity.

Preservation of attached posterior soft tissue and multiple incision on contracted common extensor helps in facilitating reduction. Divergent $\mathrm{K}$ wires or one horizontal K-wire and one oblique partial threaded screw if the fixation is not rigid enough or if the fragment is larger gives better chance of fracture union. Recent studies do not show growth disturbances by the screw. ${ }^{15-17}$ We believe burying $\mathrm{K}$-wires beneath skin facilitates early movement and functional recovery as well avoids chance of loss of reduction from earlier removal. We had no nonunion or loss of reduction despite bone graft was not used; so as Shabir et al in their series of 20 children, who underwent osteosynthesis without bone graft had no nonunion. ${ }^{3}$ We hence conclude bone grafting is not necessary if fixation is rigid enough and hardwares removed only after X-ray showing good bony union. In our study $19(86.36 \%)$ satisfactory result was seen which is comparable to series of 21 children by Saraf et al who reported $17(80.95 \%)$ satisfactory result ( $Z$ test, Z 0.48, p >0.05). ${ }^{11}$

Our average follow up was 18.05 months but longer follow-ups to evaluate long-term effect on the growth of condyle and larger sample size would have been better.

All of our fracture united with good functional outcome 
Chhetri et al. Operative Management of Late Presented Displaced Lateral Condyle..

and all of the children and parents were satisfied with the final result. We recommend osteosynthesis in late presented lateral condyle fracture of humerus in children up to 16 weeks.

\section{CONCLUSIONS}

Open reduction and internal fixation without bone grafting on late presented displaced lateral condyle fracture in children within 5 weeks gives excellent result. Osteosynthesis up to 16 weeks gives significant functional recovery, good bone alignment and union.

\section{Conflict of Interest: None.}

\section{REFERENCES}

1. Jakob R, Fowles JV, Rang M, Kassab MT. Observations concerning fractures of the lateral humeral condyle in children. J Bone Joint Surg Br. 1975 Nov;57(4):430-6. [PubMed | Full Text]

2. Dhillon KS, Sengupta S, Singh BJ. Delayed management of fracture of the lateral humeral condyle in children. Acta Orthop Scand. 1988 Aug;59(4):419-24. [PubMed]

3. Shabir A, Tahir A, Sharief A, Imtiyaz H, Shahid H, Reyaz A. Delayed operative management of fractures of the lateral condyle of the humerus in children. Malays Orthop J. 2015;9(1):18-22. [PMC | Full Text]

4. Agarwal A, Qureshi NA, Gupta N, Verma I, Pandey DK. Management of neglected lateral condyle fractures of humerus in children: A retrospective study. Indian J Orthop. 2012;46(6):698-704. [PMC | Full Text]

5. Eamsobhana P, Kaewpornsawan K. Should we repair nonunion of the lateral humeral condyle in children? Internat Orthop. 2015;39:1579-85. [Full Text]

6. Kimball JP, Glowczewskie F, Wright TW. Intraosseous blood supply to the distal humerus. J Hand Surg. 2007;32(5):642-6. [Full Text]

7. Gaur SC, Varma AN, Swarup A. A new surgical technique for old ununited lateral condyle fractures of the humerus in children. J Trauma. 1993 Jan;34(1):68-9. [ubMed | Full Text]

8. Sulaiman AR, Munajat I, Mohd EF. A modified surgical technique for neglected fracture of lateral humeral condyle in children. J Pediatr Orthop B. 2011 Nov;20(6):366-71. [PubMed]

9. Kurtulmus T, Saglam N, Saka G, Avci CC, Ugurlar M, Turker M. Paediatric lateral humeral condyle fractures: internal oblique radiographs alter the course of conservative treatment. Eur J Orthop Surg Traumatol. 2014;24(7):1130-44. [A LINK]
10. Song KS, Kang $\mathrm{CH}$, Min BW, Bae $\mathrm{KC}$, Cho $\mathrm{CH}$. Internal oblique radiographs for diagnosis of nondisplaced or minimally displaced lateral condylar fractures of the humerus in children. J Bone Joint Surg Am. 2007 Jan;89(1):58-63. [PubMed | Full Text]

11. Saraf SK, Khare GN. Late presentation of fractures of the lateral condyle of the humerus in children. Indian J Orthop. 2011;45(1):39-44. [PMC | DOI]

12. Longo UG, Franceschi F, Loppini M, Maffulli N, Denaro V Rating systems for evaluation of the elbow. Br Med Bull. 2008;87:131-161. [uuMed | Full Text]

13. Canale ST, Beaty JH. Fractures and dislocations in children In: Canale ST, Beaty JH (eds.) Campbell's Operative Orthopaedics.12th ed.Vol 2. Philadelphia; Elsevier Mosby: 2013. p.1394-8. [Full Text]

14. Pribaz JR, Bernthal NM, Wong TC, Silva M. Lateral spurring (overgrowth) after pediatric lateral condyle fractures. J Pediatr Orthop. 2012 Jul-Aug;32(5):456-60. [PubMed | DOI]

15. Frongia G, Janosi C, Mehrabi A, Schenk JP, Günthe $P$ Long-term outcome in displaced lateral humeral condyle fractures following internal screw fixation in children. Acta Orthop. Belg. 2016;82:889-95. [Full Text]

16. Stein BE, Ramji AF, Hassanzadeh H, Wohlgemut JM, Ain MC, Sponseller PD. Cannulated lag screw fixation of displaced lateral humeral condyle fractures is associated with lower rates of open reduction and infection than pin fixation. J Pediatr Orthop. 2017 Jan;37(1):7-13. [Full Text | DOI]

17. Hasler CC, Von Laer L. Prevention of growth disturbances after fractures of the lateral humeral condyle in children. J Pediatr Orthop B. 2001 Apr;10(2):123-30. [PubMed] 